\title{
Los influjos estilísticos europeos en las producciones de cerámica asturiana de la Edad Moderna ${ }^{1}$
}

\author{
Miguel Busto Zapico \\ Universidad de Oviedo \\ Programa "Severo Ochoa" de Ayudas Predoctorales
}

RESUMEN:

A través del estudio de 3.237 piezas cerámicas de cronologías que van desde el siglo XIII al XVIII queremos conocer cuáles eran los influjos estilísticos europeos en las producciones de cerámica asturiana. A comienzos de la Edad Moderna los mercados asturianos comienzan a estar inundados por cerámicas de importación, principalmente procedentes de Holanda, Talavera de la Reina, Portugal, Sevilla, País Vasco e Inglaterra. La llegada de estas producciones influirá en las decoraciones desarrolladas en los alfares asturianos de Faro de Limanes y Miranda de Avilés. En esta investigación veremos cómo en determinadas piezas asturianas aparecen motivos creados en Talavera de la Reina, Portugal, Italia, Francia e incluso Holanda. Estas influencias señalan la capacidad de la artesanía del barro asturiana de asimilar novedades, de adaptarse a las modas decorativas europeas y a las nuevas demandas de la sociedad.

\section{PALABRAS CLAVE:}

Cerámica, Faro de Limanes, Miranda de Avilés, decoración, Edad Moderna.

\section{ABSTRACT:}

Through the study of 3,237 ceramic pieces of chronologies that go from the XIII to the XVIII century, we want to know what the European stylistic influences in the production of Asturian ceramics were. At the beginning of the Early Modern Period the Asturian markets began to be flooded by imported ceramics mainly from the Netherlands, Talavera de la Reina, Portugal, Seville, the Basque Country and England. The arrival of these productions will influence the decorations developed in the Asturian potteries of Faro de Limanes and Miranda de Avilés. In this investigation we will see how in Asturian pieces, there are motifs created in Talavera de la Reina, Portugal, Italy, France and even Holland. These influences point to the ability of the Asturian mud crafts to assimilate novelties, the means of adaptation to the new European decorative forms and the demands of society.

\section{KEY WORDS:}

Pottery, Faro de Limanes, Miranda de Avilés, decoration, Early Modern Period.

\footnotetext{
Esta investigación toma como base el Capitulo V.2. Influencia de las producciones importadas sobre la producción local con cubierta de BUSTO ZAPICO, Miguel, Cerámica de importación en el Principado de Asturias entre la Baja Edad Media y la primera Edad Moderna, Universidad de Oviedo, Oviedo, Tesis Doctoral inédita, 2018. Esta Tesis Doctoral fue defendida en noviembre de 2018 obteniendo la calificación de Sobresaliente cum laude; los directores fueron la Dra. Yayoi Kawamura (Universidad de Oviedo) y el Dr. Enrico Cirelli (Università di Bologna); el tribunal estuvo formado por el Catedrático José Avelino Gutiérrez González (Universidad de Oviedo), el Catedrático Alfonso Pleguezuelo Hernández (Universidad de Sevilla), el Dr. Enrico Cirelli (Università di Bologna) y el Dr. Antonio Vannugli Nicolé (Università degli Studi del Piemonte Orientale). Agradecemos a todos ellos la ayuda prestada tanto en el proceso de investigación como en el acto de defensa.
} 
1. Los principales alfares asturianos y la llegada de cerámicas europeas

En el siglo XVII los cambios en los usos cerámicos y los gustos estéticos desarrollados en las decoraciones de las vajillas europeas fueron asumidos por parte del artesanado cerámico de Asturias. Como consecuencia de ello debió existir una progresiva especialización técnica, profesional y material en los talleres asturianos. En esta investigación abordaremos cómo algunas producciones cerámicas realizadas en la Edad Moderna en los principales centros productores de cerámica de Asturias fueron partícipes de los influjos estéticos que se sucedieron en la cerámica a escala europea. No olvidemos que la estética de la cerámica moderna europea está a su vez muy influenciada por las producciones orientales, como la porcelana China.

Para alcanzar el objetivo fijado en esta investigación partimos de los datos obtenidos a través del análisis de 3.237 piezas cerámicas que comprenden cronologías desde el siglo $\mathrm{XIII}$ al $\mathrm{XVIII}^{2}$. Se trata de piezas halladas en contextos arqueológicos fiables procedentes de excavaciones realizadas en Oviedo, Gijón, Cangas del Narcea, Avilés, Castropol, Grado y Villaviciosa (Fig. 1. A.). Dentro de las piezas estudiadas, el porcentaje más alto se corresponde con piezas de importación (76\%) y el resto de la muestra son producciones locales (24\%). Entre las producciones locales hemos incluido en este estudio las piezas dedicadas al consumo de alimentos que son utilizadas en la mesa y que tienen algún tipo de cubierta (vidriada o esmaltada). La selección se ha realizado del siguiente modo dado que lo que queríamos conocer es cómo las producciones europeas de cerámica y sus influjos estilísticos influyen sobre un grupo concreto de producciones cerámicas locales.

$\mathrm{Al}$ interior de las producciones de cerámica local hemos reconocido piezas procedentes de Faro de Limanes (15\%), Miranda de Avilés (7\%), Gijón (1\%) y Vega de Poja (1\%). En esta investigación no trataremos las producciones de Gijón y Vega de Poja por estar muy poco representadas y no ofrecer datos concluyentes. Por su parte, en los alfares de Faro de Limanes

Una selección del material cerámico analizado en: BUSTO ZAPICO, Miguel, Cerámica de importación en el..., opus cit. y Miranda de Avilés hemos observado, en algunas de sus producciones, unas decoraciones de clara influencia europea. Serán, por tanto, estos dos alfares los que centren la presente investigación.

El centro cerámico de Faro de Limanes se encuentra situado en la falda noroeste de la Sierra de la Grandota en la Parroquia de Limanes a unos $6 \mathrm{~km}$ de distancia de la capital ${ }^{3}$. Es uno de los centros alfareros más importantes de Asturias. La producción cerámica en este lugar puede rastrearse desde los siglos XI y XII ${ }^{4}$ hasta la actualidad. En Faro de Limanes se produciría cerámica negra, cerámica esmaltada y cerámica vidriada. La cerámica negra se fabricó desde los inicios del alfar ${ }^{5}$. Las cerámicas esmaltadas y cerámicas vidriadas comenzarían a producirse a finales del siglo XVI o inicios del $\mathrm{XVII}^{6}$ y no el siglo XIII como se había afirmado7.

En lo referente al alfar de Miranda de Avilés, éste se encuentra en la parroquia de Miranda perteneciente a los Ayuntamientos de Avilés y Castrillón, situado en la parte alta de ambos concejos ${ }^{8}$. En Miranda de Avilés se asentó un centro productor cerámico que estuvo en funcionamiento hasta principios del siglo XX. Se fabricaría cerámica negra, cerámica esmaltada, un gran número de caños o arcaduces para la traída de aguas ${ }^{9}$ y

IBÁÑEZ DE ALDECOA, Esperanza, "La cerámica vidriada de Faro: motivos decorativos”, en Liño: Revista anual de historia del arte, 5, 1985, pp. 235-246.

4 FANJUL PERAZA, Alfonso, TOBALINA PULIDO, Leticia, RUIZ DE ARBULO, Izaskun, ARÉVALO MUÑÓZ, Erik, CAMARERO ARRIBAS, Cristina, HERRERA MACEIRAS, Sara, y SUAREZ GARCIA, Yania, “The Medieval origins of Faro ceramics (Oviedo, Spain). Excavations at Cantu L'Rey", en Medieval Pottery Research Group, 2013, pp. 2-3; FANJUL PERAZA, Alfonso, Orixe y desendolcu de la cerámica de Faro, Conceyalía d'Educación y Cultura del Conceyu de Xixón, Gijón, 2017, p. 29.

5 FANJUL PERAZA, Alfonso, et al., "The Medieval origins ...", opus cit., pp. 2-3

6 BUSTO ZAPICO, Miguel, Cerámica de importación en el..., opus cit., pp. 1087-1220; BUSTO ZAPICO, Miguel, “Cerámica de producción local en Asturias entre los siglos XVI y XVII, procedente de las excavaciones de la casa Carbajal Solís (Oviedo, Asturias)”, en Boletín de Letras del Real Instituto de Estudios Asturianos, 185186, 2015, pp. 33-64.

7 IBÁÑEZ DE ALDECOA, Esperanza, y ARIAS, José, Faro. Mil años de producción alfarera, II vols., CAMCO, Oviedo, 1995, pp. 27, 96.

8 FEITO, José Manuel, Artesanía tradicional asturiana, Consejería de Educación y Cultura del Gobierno de Asturias, Oviedo, 1983, p. 145.

9 HEREDIA ALONSO, Cristina, Las traidas de aguas en el Cantábrico Occidental en la Edad Moderna. Gonzalo de 


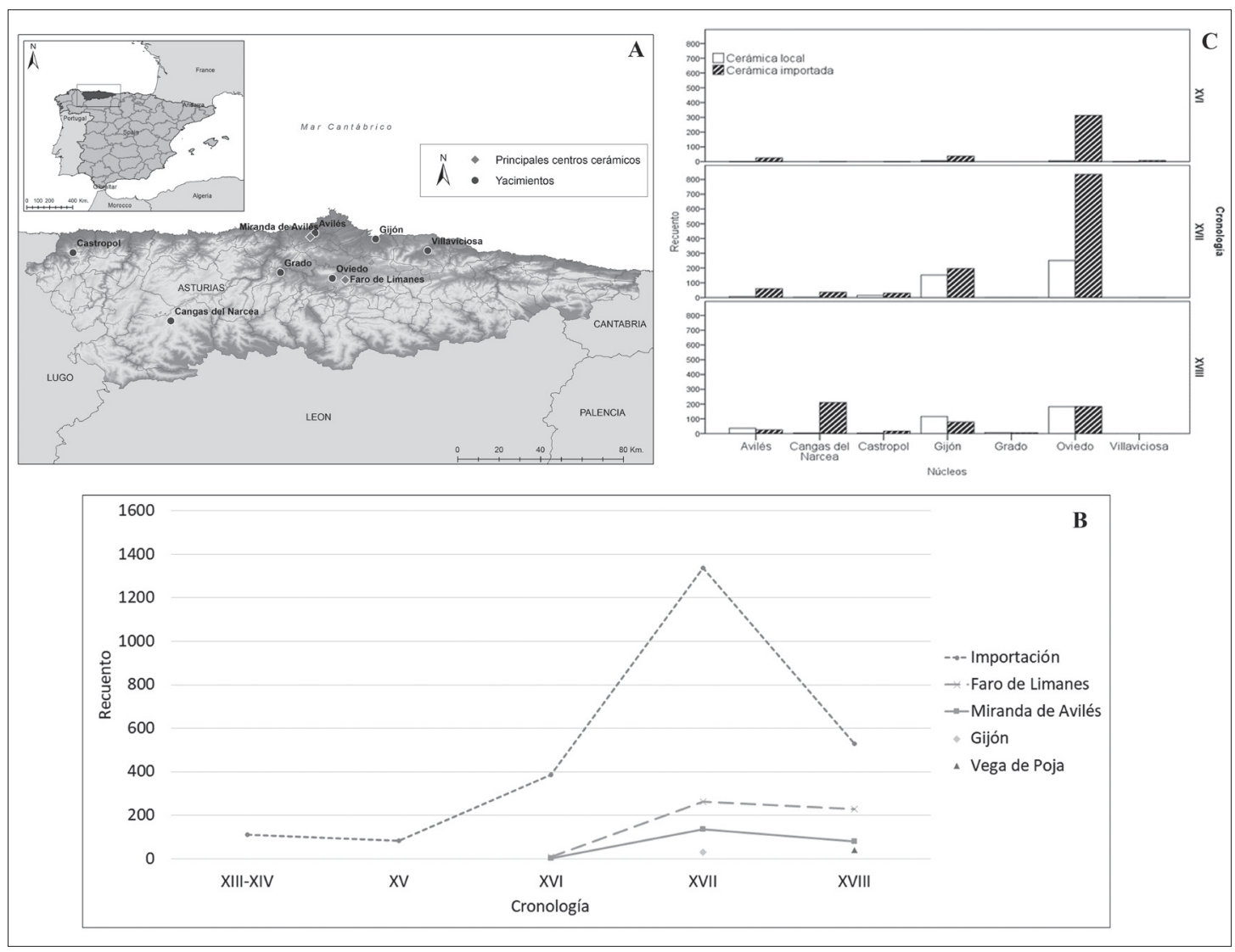

Fig. 1. A. Localización del Principado de Asturias con los yacimientos muestreados y los principales centros de producción cerámica. B. Comparativa de la evolución del consumo de cerámica local e importada en Asturias desde el siglo XIII hasta el XVIII. C. Comparativa entre la evolución del consumo de cerámica local e importada durante el periodo estudiado, dividida por los yacimientos muestreados.

también, probablemente, cerámica bermeja ${ }^{10}$. Los inicios de la actividad alfarera en Miranda aún no están esclarecidos, diferentes tesis apuntan, en lo referente al menos a las producciones de cerámica negra, a unos inicios en el siglo XIII ${ }^{11}$ o entre los siglos XIII-XV'12.

Bárcena, "Fontanero del Rey", Universidad de Oviedo, Oviedo, Tesis Doctoral inédita, 2014.

10 BUSTO ZAPICO, Miguel, Cerámica de importación en el..., opus cit., pp. 1271-1274.

11 FERNÁNDEZ, Ricardo, Alfarería tradicional de España. La Asturias alfarera, Décimas jornadas de alfarería. Avilés 2018, Fundación Municipal de Cultura de Avilés, Avilés, 2018, pp. 12-15.

12 FANJUL PERAZA, Alfonso, BUSTO ZAPICO, M., y ALONSO TOUCIDO, Francisco, "Observaciones en torno al origen y difusión de la cerámica de Miranda (Avilés)", en Arqueología y Territorio Medieval, 25, 2018, pp. 293-305. Creemos que la cerámica que aparece en la Fig. 3 podría no tratarse de una producción de Miranda de Avilés, sino que probablemente sería una importación Bajomedieval procedente del sur de la Península Ibérica. También tenemos dudas sobre la filiación a Miranda de Avilés de los fragmentos que aparecen en la Fig. 8, puesto que las asas con punciones no son comunes en el alfar asturiano. Hasta que
Aunque, probablemente, la génesis del alfar tal y como lo conocemos haya que situarla a finales del siglo $\mathrm{XVI}^{13}$. En dicha época un grupo de cañeros de origen portugués y gallego se instalarían en Miranda de Avilés de la mano de Gonzalo de la Bárcena "Fontanero del Rey" y Alonso Pérez ${ }^{14}$. Con este grupo de población comenzarían las producciones de Miranda, tanto los caños como el resto de los tipos de menaje cerámico. Por lo tanto, la actividad alfarera en Miranda de Avilés surgiría a finales del siglo XVI. Bien es cierto que es lógico suponer una actividad alfarera anterior, pero creemos que no contamos aún con datos suficientes que permitan afirmarlo.

no se realicen análisis arqueométricos la adscripción de estas piezas a Miranda debe entenderse como una hipótesis.

13 HEREDIA ALONSO, Cristina, Las traidas de aguas..., opus cit.; BUSTO ZAPICO, Miguel, Cerámica de importación en el..., opus cit., pp. 1221-1281.

14 HEREDIA ALONSO, Cristina, Las traidas de aguas..., opus cit., p. 13. 
2. El consumo de cerámica local y su relación con el consumo de piezas importadas

Hasta finales del siglo XVI o comienzos del siglo XVII no podemos defender la existencia de producciones con cubierta esmaltadas o vidriadas en Asturias ${ }^{15}$. El nacimiento de la cerámica esmaltada y vidriada asturiana está impulsado por la llegada de producciones de cerámica importada a dicha región ${ }^{16}$. Principalmente, las cerámicas estanníferas o lozas, dedicadas al servicio de mesa, serán las que impulsen estos cambios. Este menaje de importación europeo comienza a inundar los mercados asturianos desde finales del siglo XVI y sobre todo en el siglo XVII ${ }^{17}$. En el seiscientos la cerámica importada proviene principalmente de Holanda, Talavera de la Reina, Portugal, Sevilla, País Vasco e Inglaterra ${ }^{18}$.

Con el aumento en la llegada de importaciones cerámicas, los alfares locales se ven obligados a realizar cambios en su modo de producción. Crean series cerámicas muy diferentes a las que se llevaban haciendo desde el medievo, que eran principalmente formas cerradas utilizadas en la preparación de alimentos, cuya serie más común era la olla ${ }^{19}$. A comienzos de la Edad Moderna crece la producción de formas cerámicas de uso individual destinadas al consumo en la mesa de alimentos sólidos, líquidos o semilíquidos. Se hacen comunes series cerámicas como platos, cuencos o escudillas ${ }^{20}$.

A partir del siglo XVI observamos que el consumo de las producciones con cubierta locales y las producciones importadas tienen las

15 BUSTO ZAPICO, Miguel, Cerámica de importación en el..., opus cit., pp. 1087-1274; BUSTO ZAPICO, Miguel, “Cerámica de producción local...", opus cit., p. 63.

16 Estamos ante un comercio directo de piezas en el que las cerámicas tienen un valor comercial per se, hay que diferenciarlo de los contenedores cerámicos que, si bien también son cerámica de importación, en este caso, el valor radica en la mercancía que transportan.

17 BUSTO ZAPICO, Miguel, Cerámica de importación en el..., opus cit., pp. 1380-1408.

18 Para un estudio en profundidad de las producciones cerámicas importadas en Asturias durante el siglo XVII consultar: BUSTO ZAPICO, Miguel, Cerámica de importación en el..., opus cit., pp. 1393-1408.

19 FEITO, José Manuel, Cerámica tradicional asturiana, Editora Nacional, Madrid, 1985; IBÁÑEZ DE ALDECOA, Esperanza, y ARIAS, José, Faro. Mil años..., opus cit.; FERNÁNDEZ, Ricardo, Alfarería tradicional..., opus cit.; BUSTO ZAPICO, Miguel, "Cerámica de producción local...", opus cit.

20 BUSTO ZAPICO, Miguel, Cerámica de importación en el..., opus cit., pp. 1087-1274. mismas tendencias en su compraventa en los mercados asturianos. Su consumo comienza en el siglo XVI, se hace más alto en el siglo XVII y decae, en este caso ligeramente, en el siglo XVIII (Fig. 1. B.). Este paralelismo entre las tendencias observables en las producciones importadas y las locales, señala claramente su relación. De este modo, cuanto más se consumen cerámicas importadas, más se consumen las producciones esmaltadas o vidriadas locales. Del mismo modo, cuando la demanda de producciones cerámicas importadas decae, ocurre lo mismo con las esmaltadas y vidriadas locales.

El análisis comparativo entre los diferentes núcleos de población analizados nos indica cómo, en el siglo XVI, el menaje cerámico que se utilizaría en las mesas asturianas era principalmente importado (Fig. 1. C.). En el siglo XVII, la tendencia es la misma y vemos como paralelamente al crecimiento en el consumo de cerámica importada, crece también el consumo de producciones locales con cubierta. En el siglo XVIII, observamos un cambio en esta situación: en los núcleos de Gijón y Avilés es mayor el número de piezas locales con cubierta, por encima de las importadas. En Oviedo, que había sido el gran foco de consumo de cerámica importada, su número decae y se muestra el mismo nivel que las producciones locales. En Cangas del Narcea, la situación es casi la inversa: apenas tenemos producciones locales con cubierta, sino que lo que se consume son principalmente lozas importadas. Esto se debe a que hemos estudiado las cerámicas procedentes del Monasterio de San Juan Bautista de Corias, uno de los centros asturianos de poder más importantes en el siglo XVIII ${ }^{21}$.

A través de la evolución en su consumo creemos que podemos tratar de discernir los grupos sociales a los que las producciones con cubierta locales iban dirigidas. Con la llegada de producciones importadas, principalmente formas de mesa con cubierta esmaltada blanca y diferentes decoraciones, las clases sociales más adineradas se hicieron con este menaje de proveniencias muy diversas. Las capas más populares de la sociedad asturiana, también influidas por las modas y la estética del momen-

\footnotetext{
GARCÍA ÁLVAREZ-BUSTO, Alejandro, Arqueología de la Arquitectura Monástica en Asturias: San Juan Bautista de Corias, Dirección General de Patrimonio Cultural, Oviedo, 2016.
} 
to, abandonarían el menaje que se venía utilizando desde el medievo y tratarían de acceder a estos nuevos productos. Es de suponer que los elevados precios de las cerámicas importadas las hiciesen inaccesibles a las clases más populares. Esta situación debió de llevar a los alfares locales (principalmente Faro de Limanes y Miranda de Avilés) a producir formas que trataban de imitar las cerámicas importadas para satisfacer esta demanda más popular.

\section{Los influjos estilísticos europeos en las producciones de cerámica asturiana del siglo XVII.}

Las producciones con cubierta (vidriada o estannífera) que se realizan en Faro de Limanes y Miranda de Avilés desde finales del siglo XVI serán piezas de una calidad aceptable. El acabado, sobre todo por la escasez de estaño y plomo, no será nunca tan bueno como en el resto de la cerámica de mesa con cubierta que se está vendiendo en los mercados asturianos con procedencias muy diversas.

Las piezas con cubierta locales debían de ser una producción bien considerada dado que fueron objeto de comercio regional y también suprarregional. Las piezas de Faro de Limanes eran vendidas en los mercados de Oviedo, Gijón, Grado, Avilés y Villaviciosa, a donde llegaban en carros del país arrastrados por bueyes ${ }^{22}$. Además, su producción va a extenderse fuera de Asturias llegando a Galicia ${ }^{23}$ (por el momento se ha atestiguado su presencia en Pontevedra $^{24}$, Vigo ${ }^{25}$ y A Coruña ${ }^{26}$ ) y Bilbao ${ }^{27}$. Una or-

22 FEITO, José Manuel, Cerámica tradicional..., opus cit., p. 134.

23 FEITO, José Manuel, Cerámica tradicional..., opus cit., p. 134.

24 ALONSO TOUCIDO, Francisco, "Sondaxes arqueolóxicas valorativas no contexto da rehabilitación integral de vivenda na Rúa Conde de San Román, n¹3, Pontevedra", Memoria Arqueológica, 2017, p. 26.

25 ALONSO TOUCIDO, Francisco, "Proxecto de sondaxes arqueolóxicas valorativas no contexto do troco de distribución de vivenda na praza de Pescadores $n^{\circ} 3$, Vigo", Memoria Arqueológica, 2017, p. 18.

26 PÉREZ IGLESIAS, Andrea, SÁNCHEZ BLANCO, Fátima, FERNÁNDEZ ABELLA, David, "Una contribución a la arqueología subacuática gallega y su problemática: Materiales arqueológicos localizados en el puerto de Testal, Ría de Muros e Noia (A Coruña)", en IX Jornadas de Jóvenes en Investigación Arqueológica, IIIPC, Santander, 2018, pp. 543-549.

27 FEITO, José Manuel, Cerámica tradicional..., opus cit., p. 134. denanza del Ayuntamiento de Oviedo de 1773 dispone ubicar a los vendedores de verduras y demás legumbres tras "las carnicerías y al lado de ellos la talavera de Faro" ${ }^{28}$. Lo que nos indica una asimilación por parte de los asturianos entre las lozas de talavera y la cerámica local con cubierta.

En el caso de Miranda de Avilés también tenemos atestiguada, al menos en el siglo XVIII, la venta de sus piezas en mercados fuera de Asturias, puesto que "cuando se trabaja se arrebata de las manos de los fabricantes; consúmese en Asturias y en toda nuestra costa septentrional desde Vizcaya a Galicia" ${ }^{29}$. Los arcaduces serían las piezas de Miranda con mayor salida comercial $^{30}$, aunque no debemos minusvalorar la movilidad y demanda del resto de producciones. Movimientos comerciales de "jarras" y "jarros" entre Avilés y Bilbao han quedado reflejados en la documentación ${ }^{31}$. Investigaciones recientes señalan la aparición de algunas supuestas piezas de Miranda en Santiago de Compostela ${ }^{32}$.

La expansión comercial de las producciones de Faro de Limanes y Miranda de Avilés fuera de Asturias permite poder considerar estas cerámicas como satisfactorias para un mercado suprarregional limitado al norte de la Península Ibérica. Probablemente su valor comercial fuese menor que el otorgado al resto de producciones cerámicas importadas, por lo que serían más accesibles a las clases populares.

La influencia de las producciones importadas sobre la producción local con cubierta se va a notar en la aparición de nuevas formas destinadas al consumo individual en la mesa (platos, cuencos y escudillas, principalmente). No obstante, será en la ornamentación de las piezas asturianas donde podemos observar una

${ }_{28}$ MIGUEL VIGIL, Ciriaco, Colección histórico-diplomática del Ayuntamiento de Oviedo, Pardo, Gusano y Compañía, Oviedo, 1889, p. 442.

29 Extracto de los Diarios (1790-1794) de Melchor Gaspar de Jovellanos, Diario IV Itinerario VIII, fechado el jueves 2 de agosto de 1792. En CASO GONZÁLEZ, José Miguel, y GONZÁLEZ SANTOS, Javier, Obras completas de Jovellanos, Vol. VI, KRK ediciones, Gijón, 2011, pp. 450-451.

30 HEREDIA ALONSO, Cristina, Las traídas de aguas..., opus cit., p. 395.

31 RODRÍGUEZ FERNÁNDEZ, Perfecto, "El concejo de El Franco según el Catastro del marqués de la Ensenada", en Boletín del Instituto de Estudios Asturianos, 1989, pp. 165-190.

32 FANJUL PERAZA, Alfonso, et al., "Observaciones en torno al...”, opus cit., pp. 300-302. 
relación clara con los talleres europeos más importantes de la Edad Moderna. Cuando en Faro y en Miranda reproducian una decoración típica de otro taller parecen hacerlo de forma automática, perdiendo parte del posible significado simbólico de los originales. Estamos ante una reinterpretación asturiana de los motivos decorativos de moda en Europa, los cuáles al mismo tiempo reinterpretan la estética y las decoraciones de las piezas asiáticas, principalmente de las porcelanas chinas.

\subsection{Los influjos estilisticos europeos en Faro de Limanes}

Hemos encontrado similitudes entre diferentes producciones de Faro de Limanes y decoraciones granadinas, talaveranas, portuguesas y holandesas. También señalaremos ciertos paralelismos con piezas italianas y francesas. Hay quien ha relacionado alguna de las decoraciones de Faro con motivos persas ${ }^{33}$, aunque en nuestra opinión dichas similitudes se deben más a coincidencias en motivos geométricos que a una propia y verdadera influencia directa.

Entre las producciones de Faro de Limanes una decoración destaca por encima del resto, se trata de la páxara, presente de manera exclusiva en la tipología Faro Esmaltada con amarillo y negro - Plato $I^{4}$ (Fig. 2. A.). Apolinar de Rato y Hevia en su Vocabulario de las palabras $y$ frases bables de 1891, al referirse a la voz Faro, dice que aquí se fabricaban "los platos de páxara tan celebrado para comer huevos estrellaos" 35 . La pieza más antigua con el motivo de la páxara procede de un contexto arqueológico del siglo XVII y la decoración continuaría produciéndose en el siglo XVIII ${ }^{36}$. Por el momento no hay datos concluyentes, pero el motivo podría haber desaparecido en el siglo XIX para retomarse en el siglo XX con el influjo de las artesanías populares, convirtiéndose en uno de los emblemas de la cerámica esmaltada tradi-

33 IBÁÑEZ DE ALDECOA, Esperanza, "La cerámica vidriada de Faro...", opus cit., p. 241.

34 BUSTO ZAPICO, Miguel, Cerámica de importación en el..., opus cit., pp. 1155-1158.

35 RATO Y HEVIA, Apolinar, Vocabulario de las palabras $y$ frases bables que se hablaron antiguamente $y$ de las que hoy se hablan en el Principado de Asturias, seguido de un compendio gramatical Tipografía de Manuel Ginés Hernández, Madrid, 1891.

36 BUSTO ZAPICO, Miguel, Cerámica de importación en el..., opus cit., p. 1158. cional asturiana. En la actualidad la páxara se desarrolla sobre todo tipo de piezas y es un motivo recurrente y común, mientras que en la Edad Moderna parece ser un motivo extraordinario $^{37}$.

La páxara es la representación zoomorfa por excelencia de la cerámica faruca ${ }^{38}$, en ella se ha "logrado una metamorfosis en la que pájaro y pez han llegado a formar un único elemento indefinido con caracteres de ambos animales" 39 . Quizá se esté representando aquí el pez femenino llamado Salonga, que podía vivir en el mar y en la tierra ${ }^{40}$. De la Salonga se dice que:

"volaba como un pájaro y se posaba en los árboles. Tenía rabo de vaca, comía hierba tierna y espuma de mar. Salía entre la noche y el día, se escondía entre las rocas o en el bosque y había que procurar no mirarla. Esta creencia popular advierte que, si alguien se bañaba en soledad y la veía, le empezaban a salir escamas y se convertía en pez, viviendo en el mar para siempre. Por eso, cuando aparecían las primeras escamas, tenía que alejarse de la Salonga y frotarse con espuma de mar, estando en ayunas y acompañado, repitiendo el ritual durante nueve días seguidos"41.

El motivo de la páxara es propio y una invención faruca, aun así, conviene señalar ciertas similitudes con producciones europeas anteriores y muy diferentes entre sí. Existen paralelos con producciones italianas de protomaiolica fabricadas en Puglia en el siglo XII ${ }^{42}$. Del mismo modo, el motivo de la páxara guarda

37 De las más de tres mil piezas analizadas la páxara solo ha aparecido en dos fragmentos. En el último catálogo publicado con producciones esmaltadas elaboradas en la actualidad en Faro de las 15 piezas que recoge, en tres de ellas aparece la páxara (FERNÁNDEZ, Ricardo, Alfarería tradicional..., opus cit., pp. 148-162).

38 IBÁÑEZ DE ALDECOA, Esperanza, y ARIAS, José, Faro. Mil años..., opus cit., p. 94.

39 IBÁÑEZ DE ALDECOA, Esperanza, Cerámica tradicional de Faro, Servicio de Publicaciones del Principado de Asturias, Oviedo, 1987, p. 107.

40 FERNÁNDEZ, Ricardo, Alfarería tradicional..., opus cit., p. 47.

41 FERNÁNDEZ, Ricardo, Alfarería tradicional..., opus cit., p. 47.

42 BERTI, Graziella, GIORGIO, Marcella, Ceramiche con coperture vetrificate usate como "bacini". Importazioni a Pisa e in altri centri della Toscana tra fine X e XIII secolo, Ricerche di Archeologia Altomedievale e Medievale, All'Insegna del Giglio, 2010, pp. 55-56, fig. 76. 
A
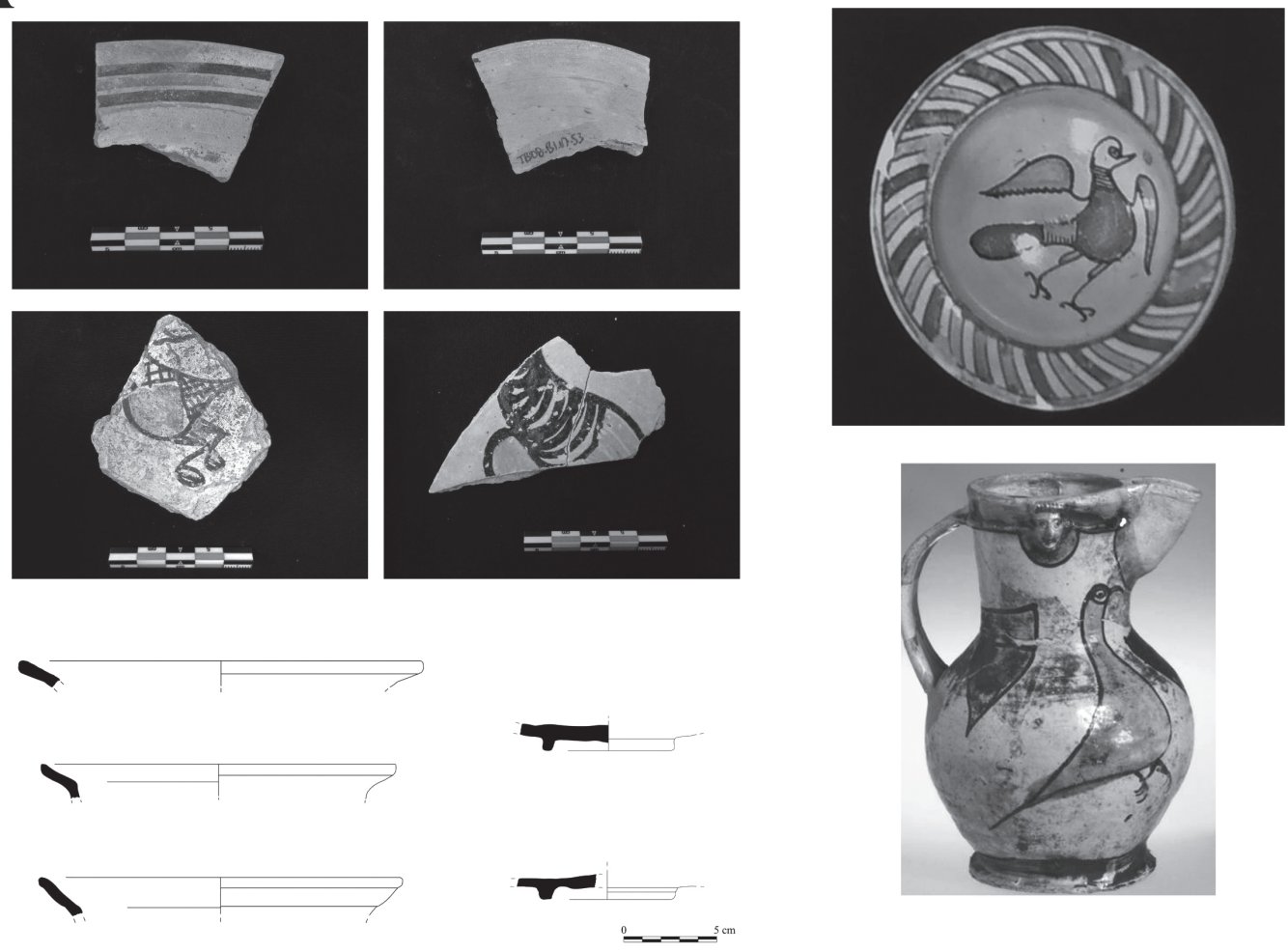

\section{B}
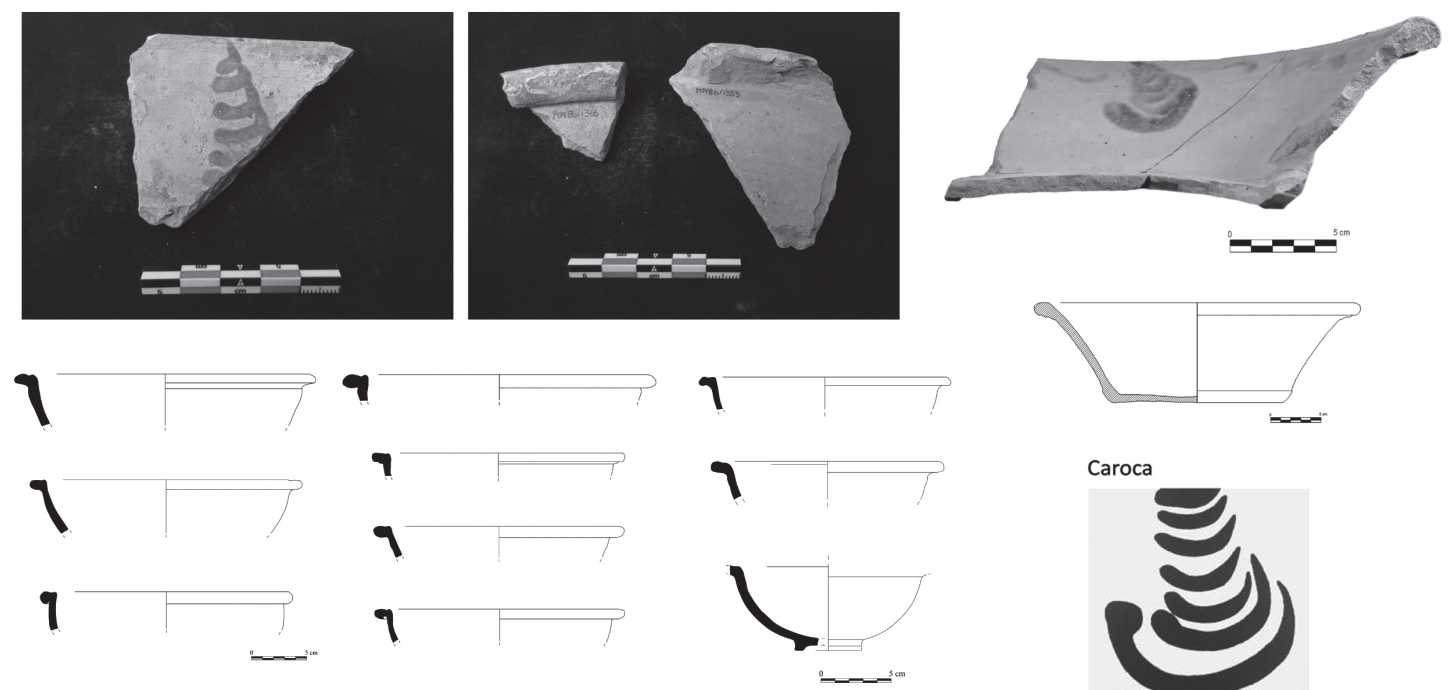

Fig. 2. A. Similitudes entre la páxara de Faro de Limanes y otras decoraciones realizadas en Europa. Columna izquierda: Faro Esmaltada con amarillo y negro - Plato I; columna derecha franja superior: plato de protomaiolica italiana, Puglia (Italia), siglo XII (BERTI, Graziella, GIORGIO, Marcella, Ceramiche..., opus cit., pp. 55-56, fig. 76); columna derecha franja inferior: jarrita hallada en Southampton, Saintonge (Francia), siglos XIII-XIV (HAGGARTY, George, A Gazetteer ..., opus cit., p. 24). B. Imitación faruca de un motivo granadino de Fajalauza. Columna izquierda: Faro Esmaltada con verde - Fuente I; columna derecha franja superior: Lebrillo VI Fajalauza, Granada, siglos XVII-XVIII (BUSTO ZAPICO, Miguel, “Una aproximación...”, opus cit., pp. 117-132); columna derecha franja inferior: decoración de carocas (GARZÓN CARDENETE, José Luis, Cerámica..., opus cit., pp. 282-283, 366). 
cierta relación con las producciones polícromas de Saintonge (Francia), que se elaboran entre finales del siglo XIII, pudiendo llegar hasta principios del $\mathrm{XV}^{43}$. Resulta cuanto menos singular que la composición del dibujo de la páxa$r a$ asturiana es muy similar al que observamos en la protomaiolica italiana con la posición del animal, las alas abiertas, las garras de las patas y sobre todo la conformación del dibujo con un rallado que marca el cuello y el inicio de la cola, mientras que el vientre está pintado de manera monocroma. Al mismo tiempo también recuerda al dibujo de algunos animales en la serie tricolor de Talavera de la Reina.

Parece existir cierta coincidencia, en este caso no sabemos si es una sinergia casual, entre una decoración faruca y otra típica de las producciones granadinas de Fajalauza de los siglos XVII-XVIII ${ }^{44}$ (Fig. 2. B.). La tipología Faro Esmaltada con verde - Fuente $I^{45}$ comienza su producción en el siglo XVII y continúa, de manera ininterrumpida, hasta el XIX. Es posible que tenga sus inicios a finales del siglo XVI, pero por ahora no tenemos contextos lo suficientemente claros como para probarlo de manera fehaciente. Esta tipología de fuente de Faro puede aparecer decorada con una serie de pinceladas o arcos superpuestos, con una clara orientación vertical y en disminución o aumento progresivo, muy similar al motivo llamado de las "carocas" de la cerámica de Fajalauza"

Los motivos de las producciones de Talavera de la Reina parecen ser los que más influyen sobre las cerámicas de Faro de Limanes (Fig. 3. A.). De este modo, tenemos diferentes decoraciones que recuerdan a las talaveranas, sobre todo a las series polícromas de este cen-

43 ALlAN, J. P., Medieval and post-medieval finds from Exeter, 1971-1980, Exeter Archaeological Reports, Vol. 3, Exeter City Council, University of Exeter, Exeter, 1984, p. 23; HAGGARTY, George, A Gazetteer and Summary of French Pottery in Scotland c 1150 - c 1650, National Museums of Scotland, Edimburgo, 2006, p. 24.

44 GARZÓN CARDENETE, José Luis, Cerámica de Fajalauza, Albaida, Granada, 2004, pp. 282-283, 366; BUSTO ZAPICO, Miguel, "Una aproximación a las cerámicas recuperadas en la excavación arqueológica del restaurante de El Polinario", en @rqueología y Territorio, 10, 2014, pp. 117-132.

45 BUSTO ZAPICO, Miguel, Cerámica de importación en el..., opus cit., pp. 1127-1130.

46 GARZÓN CARDENETE, José Luis, Cerámica de..., opus cit., pp. 282-283, 366. tro toledano ${ }^{47}$. La tipología Faro Esmaltada con amarillo y negro - Cuenco $I^{48}$ se desarrolla en Faro durante los siglos XVII y XVIII, del mismo modo, también puede estar presente en algunos contextos del XIX, aunque de manera residual. Estos cuencos pueden presentar una decoración formada por franjas en amarillo y negro que se repiten tanto en el borde como en el fondo. Estas franjas tienen paralelos claros en las orlas o listeles que marcan los límites de las composiciones en las series polícromas de Talavera de la Reina y Puente del Arzobispo. Del mismo modo, en una pieza elaborada en Faro de Limanes ${ }^{49}$, el alfarero trató de reproducir el tema del pino $^{50}$, tan característico de la serie polícroma de Talavera de la Reina y sobre todo de Puente del Arzobispo.

De igual manera, hemos observado una imitación de diferentes motivos portugueses (Fig. 3. B.). Una de las más claras es la ornamentación en forma de espiral que investigadores lusos han interpretado como la corola de una flor ${ }^{51}$. Esta decoración está presente en platos, cuencos y escudillas fabricados en Vila Nova $^{52}$ y Coímbra ${ }^{53}$ en el siglo XVII. En las producciones farucas aparece en la tipología Faro Esmaltada con verde - Cuenco $I B^{54}$ que comienza a producirse a finales del siglo XVI, continuando de manera ininterrumpida hasta la actualidad ${ }^{55}$. En los cuencos farucos el motivo desarrollado en el fondo es una espiral cuyo centro es el del mismo cuenco. Estos cír-

47 SESEÑA, Natacha, "Talavera y Puente del Arzobispo", en Cerámica esmaltada española, Labor, Barcelona, 1981, pp. 75-92; PLEGUEZUELO HERNÁNDEZ, Alfonso, "Luces y sombras sobre las lozas de Talavera", en Lozas y Azulejos de la colección Carranza, Junta de Comunidades de Castilla-La Mancha, Toledo, 2002, pp. 229-463.

48 BUSTO ZAPICO, Miguel, Cerámica de importación en el..., opus cit., pp. 1152-1155.

49 IBÁÑEZ DE ALDECOA, Esperanza, y ARIAS, José, Faro. Mil años..., opus cit., p. 105.

50 BUSTO ZAPICO, Miguel, “Cerámica de producción local...”, opus cit., pp. 62-63, fig. 20.

51 VARELA GOMES, Mário, y CASIMIRO, Tânia Manuel, On the World's Routes. Portuguese Faience (16th-18th centuries), Instituto de Arqueologia e Paleociências, Universidade Nova de Lisboa, Lisboa, 2013, p. 53.

52 VARELA GOMES, Mário, y CASIMIRO, Tânia Manuel, On the World's..., opus cit., p. 53.

53 VARELA GOMES, Mário, y CASIMIRO, Tânia Manuel, On the World's..., opus cit., p. 34.

54 BUSTO ZAPICO, Miguel, Cerámica de importación en el..., opus cit., pp. 1122-1124.

55 BUSTO ZAPICO, Miguel, Cerámica de importación en el..., opus cit., p. 1124. 


\section{A}
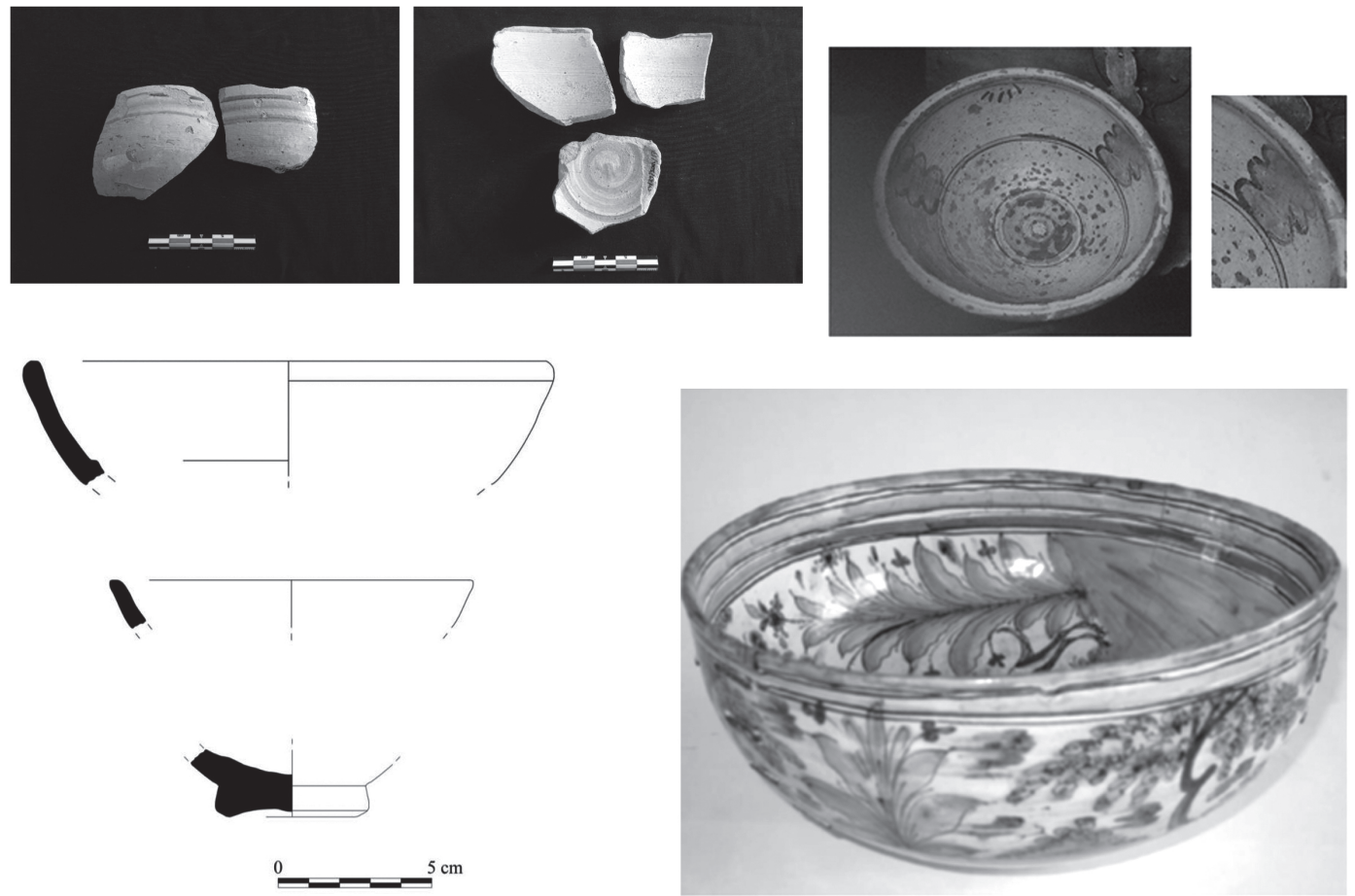

B
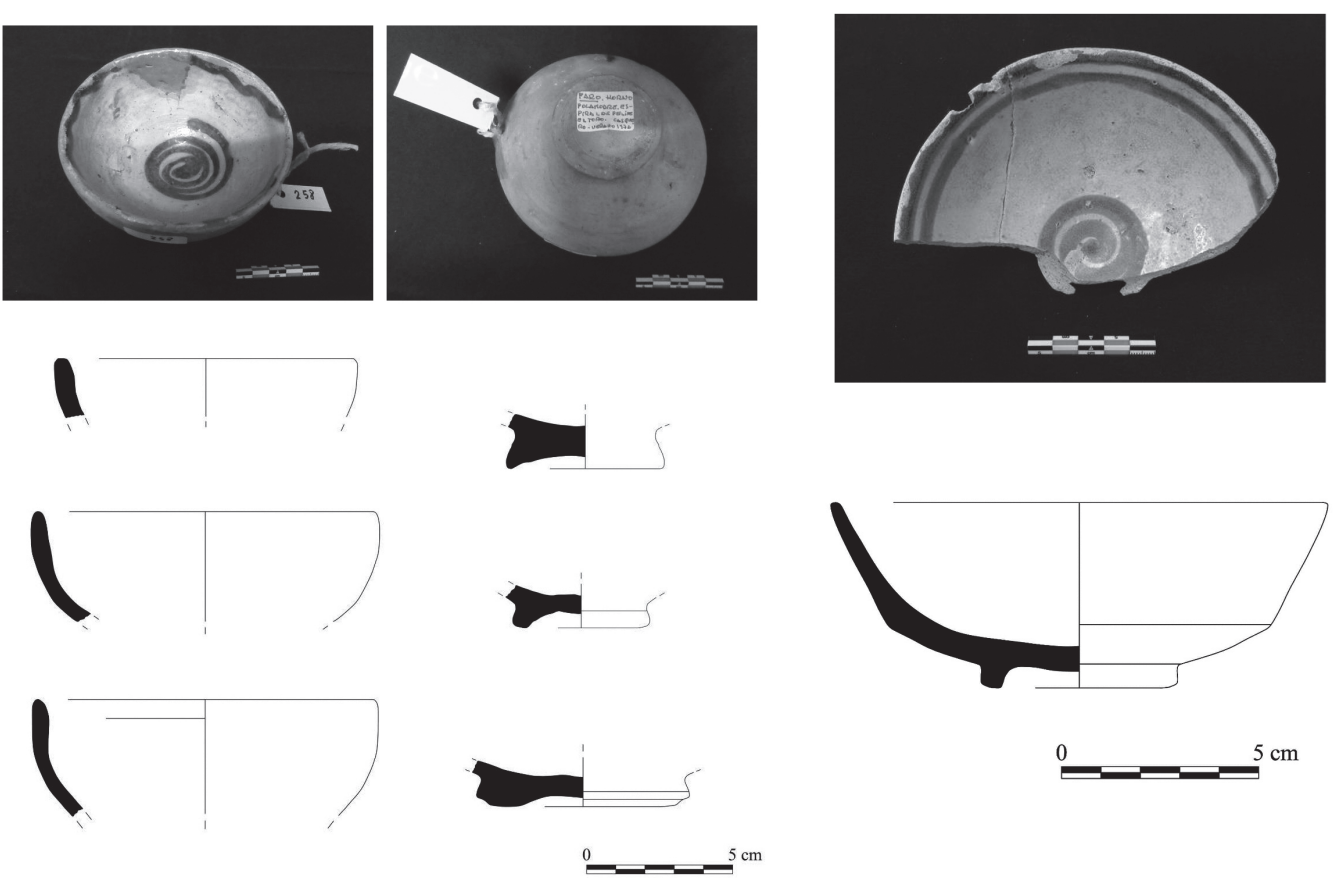

Fig. 3. A. Imitación faruca de motivos talaveranos. Columna izquierda: Faro Esmaltada con amarillo y negro - Cuenco I; columna derecha franja superior: fuente de Faro (IBÁÑEZ DE ALDECOA, Esperanza, y ARIAS, José, Faro. Mil años ..., opus cit., p. 105) decorada con el tema del pino; columna derecha franja inferior: cuenco policromo de Talavera de la Reina (Museo Nacional de Artes Decorativas, Madrid, inventario: CE03472). B. Imitación faruca de motivo portugués. Columna izquierda: Faro Esmaltada con verde - Cuenco IB; columna derecha: escudilla fabricada en Coímbra (BUSTO ZAPICO, Miguel, Cerámica de importación en el..., opus cit., pp. 543-545) en la segunda mitad del siglo XVII (VARELA GOMES, Mário, y CASIMIRO, Tânia Manuel, On the World's..., opus cit., p. 34). 
culos o espirales aparecen "en los centros de las escudillas, o más frecuentemente formando un rosario de círculos contiguos que solían incluir en los bordes de los platos" ${ }^{26}$. Bien es cierto que se trata de un motivo muy sencillo, pero las similitudes entre la decoración portuguesa y la faruca, y que se den de manera contemporánea en el siglo XVII, nos inducen a pensar que algún alfarero de Faro de Limanes se inspiró en la decoración lusa.

Uno de los motivos más claros imitados por Faro de Limanes es la orla dibujada en el ala de la tipología Faro Esmaltada con verde, amarillo y negro - Plato $I^{57}$. Se trata de una tipología faruca del siglo XVIII que está imitando la orla que decora el ala de una producción holandesa de faience, realizada en Delft en la primera mitad del siglo XVII ${ }^{58}$ (Fig. 4. A.). En la pieza holandesa la orla se desarrolla en el ala del plato de manera monocroma en azul. En el caso faruco, se trata de una cenefa delimitada por dos líneas en verde, que marcan los límites del ala del plato y crean un espacio en el que se desarrolla una decoración geométrica en la que elipses silueteadas en negro y coloreadas en amarillo crean espacios triangulares en cuyo centro se ha pintado un pequeño círculo negro. Por lo tanto, el pintor asturiano de esta pieza dotó al motivo de mayor complejidad al darle policromía. A su vez esta orla pudo influir en otras decoraciones de Faro, una de ellas sería la línea "que aparece en los bordes de los platos y que se ve completada por puntos en amarillo en los espacios intermedios" ${ }^{5}$. Otra posible serie influenciada podría tratarse de la conocida como "de hojas contrapuestas" 60.

Esta orla tan compleja, no será el único motivo que Faro de Limanes tome de Holanda (Fig. 4. B.). Las tipologías Faro Vidriada - Cuenco $I^{61}$, Faro Vidriada - Plato $I B^{62}$ y Faro Vidriada

56 IBÁÑEZ DE ALDECOA, Esperanza, Cerámica tradicional..., opus cit., pp. 104-105.

57 BUSTO ZAPICO, Miguel, Cerámica de importación en el..., opus cit., pp. 1184-1187.

58 Plato, Delft (Holanda), 1630-1650. Inventario: BK1975-41, Rijksmuseum, Ámsterdam. Consultado en: https://www.rijksmuseum.nl/en/collection/BK-1975-41.

59 IBÁÑEZ DE ALDECOA, Esperanza, Cerámica tradicional..., opus cit., p. 104.

60 IBÁÑEZ DE ALDECOA, Esperanza, Cerámica tradicional..., opus cit., p. 105.

61 BUSTO ZAPICO, Miguel, Cerámica de importación en el..., opus cit., pp. 1195-1196.

62 BUSTO ZAPICO, Miguel, Cerámica de importación en el..., opus cit., pp. 1199-1200.
- Orza $I^{63}$, todas ellas fechadas en el siglo XVIII o a finales del siglo XVII, tienen paralelos en su acabado y decoración con piezas holandesas del mismo periodo ${ }^{64}$. Las piezas vidriadas de Faro son poco comunes, dado que el vidriado se usó "en pequeña proporción y en momentos en que era difícil conseguir el estaño" ${ }^{\text {. }}$. Esto ha hecho que "la cerámica vidriada y por tanto de una cubierta de plomo sea la menos frecuente en Faro de Limanes" ${ }^{\prime 6}$. Por el momento, la mayor colección en contexto arqueológico es la hallada en el horno de Ca Xuanín datada entre los siglos XVII y XVIII ${ }^{67}$. La relación entre las producciones vidriadas de Faro y los paralelos con piezas holandesas tanto en el cromatismo de las piezas (en ambos casos se juega con un fondo amarillento sobre el que toma forma una decoración parda) como en la forma de ejecutar la decoración (una suerte de esponjado), podría sugerirnos que toda esta producción faruca tan singular surgiría a raíz de la llegada a Asturias de piezas holandesas.

\subsection{Los influjos estilísticos europeos en Miranda de Avilés}

En el caso de Miranda de Avilés, las influencias encontradas están circunscritas exclusivamente a Talavera de la Reina en lo referente a las piezas con cubierta. En lo tocante a la cerámica negra, podemos intuir ciertas similitudes con producciones gallegas y portuguesas, pero que aún no estamos en posición de señalarlas con rotundidad. Por lo que respecta a la cerámica bermeja de Miranda de Avilés, aunque

${ }_{63}$ BUSTO ZAPICO, Miguel, Cerámica de importación en el..., opus cit., pp. 1205-1206.

64 GAWRONSKI, Jerzy, JAYASENA, Ranjith, LAGERWEIJ, Ab, OSTKAMP, Sebastiaan, TOUSAIN, Ron, y VEERKAMP, Jorgen, "Catalogue of archaeological ceramics from Amsterdam 1175-2011", en Amsterdam Ceramics. A city's history and an archaeological ceramics catalogue 1175-2011, Uitgeverij Bas Lubberhuizen, Spruijt, 2012, pp. 279, 362; JASPERS, Nina Linde, y SCHEFFER-MUD, C., "Catalogus keramiek en glas van de opgraving Oostzaan-Kerkbuurt”, en Hollandia archeologen, 272, 2, 2009, pp. 50, fig. 41.

65 IBÁÑEZ DE ALDECOA, Esperanza, y ARIAS, José, Faro. Mil años..., opus cit., pp. 27, 96.

66 DIEGO SOMOANO, Celso, SAVINI CELIO, Sergio, BOLADO RODRÍGUEZ, Javier, BLANCO DEL DAGO, Maximino, La cerámica en el museo Basilio Sobrecueva, Concejalía de Cultura del Ayuntamiento de Oviedo, Oviedo, 2001, p. 16.

67 FANJUL PERAZA, Alfonso, Orixe y desendolcu..., opus cit., pp. 41-45. 
A
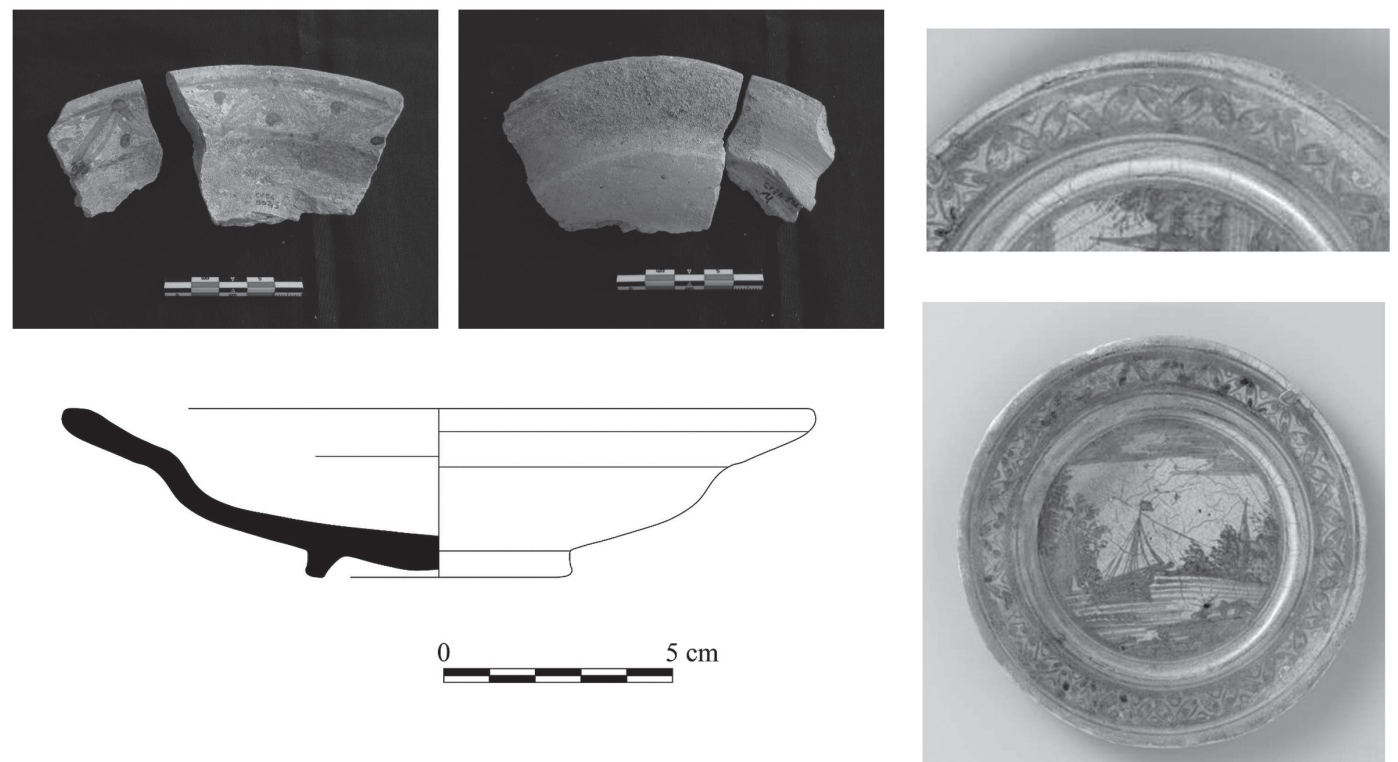

B
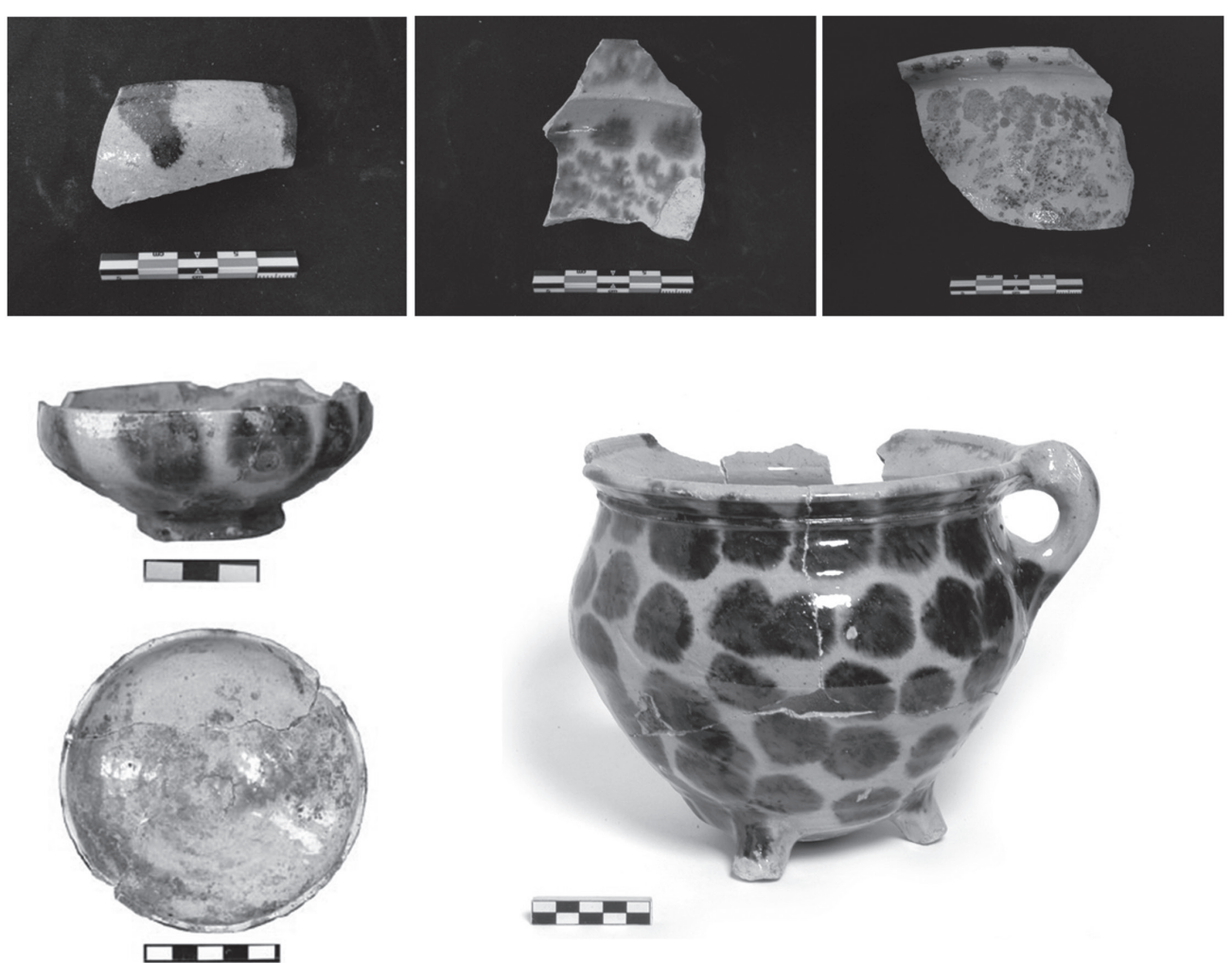

Fig. 4. A. Imitación faruca de un motivo de faience holandesa. Columna izquierda: Faro Esmaltada con verde, amarillo y negro - Plato I; columna derecha: plato, Delft (Holanda), 1630-1650 (Rijksmuseum, Ámsterdam, inventario: BK-1975-41). B. Imitaciones farucas de piezas vidriada holandesas. Franja superior de izquierda a derecha: Faro Vidriada - Cuenco II, Faro Vidriada - Plato IB y Faro Vidriada - Orza I; franja inferior de izquierda a derecha: cuenco, Holanda, 1700-1800 (JASPERS, Nina Linde, SCHEFFER-MUD, C., "Catalogus...", opus cit., pp. 50, fig. 41) y orza, Frisia (Holanda), 1675-1725 (GAWRONSKI, Jerzy, et al., "Catalogue...”, opus cit., pp. 279, 362). 
su estudio es aún muy inicial podemos señalar algunas similitudes en las formas y en el acabado de estas piezas con la cerámica portuguesa conocida como vermelha y fabricada en el Alto Alentejo, Pombal, Lisboa, Aveiro, Coímbra y Silves, desde el siglo XV al XVIII ${ }^{68}$. Creemos que la tipología de alguna de las piezas mirandesas tanto de las producciones negras como de las bermejas habría que ponerlas en relación con la llegada de alfareros gallegos y portugueses a Miranda de Avilés a finales del siglo XVI. Estos artesanos traerían consigo su forma de trabajar el barro y sus tipologías cerámicas.

En cuanto a las producciones esmaltadas de Miranda, las piezas que están decoradas en azul imitan claramente, aunque de una forma un tanto inocente, a la serie helechos y la serie helechos tardios de Talavera de la Reina (Fig. 5). La primera de ellas se produce entre 1620 y $1725^{69}$, aunque pudo empezar con anterioridad $^{70}$; mientras que la serie helechos tardios se desarrollaría en el siglo XVIII ${ }^{71}$. La decoración en forma de hojas de helecho también se da en piezas de loza portuguesa realizadas durante el siglo XVII en Vila Nova ${ }^{72}$ y Lisboa ${ }^{73}$. Por su parte, las series de Miranda decoradas en azul se elaboran en los siglos XVII y XVIII de manera casi exclusiva ${ }^{74}$. En Miranda, los helechos o las "ramitas en azul" aparecen en un buen número de tipologías: Miranda Esmaltada con azul - Cuenco II, Miranda Esmaltada con azul - Cuenco III, Miranda Esmaltada con azul - Fuente II, Miranda Esmaltada con azul Plato I, Miranda Esmaltada con azul - Plato II, Miranda Esmaltada con azul - Plato IV y Miranda Esmaltada con azul - Jarrita/o $\Gamma^{5}$. Todas

68 NEWSTEAD, Sarah, y CASIMIRO, Tânia Manuel, "A Cerâmica Portuguesa no Atlântico Norte (Séculos XVII-XVIII) o iniciar de um projecto de investigação", en Almadan online, 19, 2015, pp. 64-69.

69 GONZÁLEZ ZAMORA, César, Talaveras, Grupo Antiquitas S.L., Madrid, 2004, pp. 137-149.

70 PLEGUEZUELO HERNÁNDEZ, Alfonso, "Luces y sombras...", opus cit., p. 252.

71 GONZÁLEZ ZAMORA, César, Talaveras, opus cit., p. 149.

72 SEBASTIAN, Luís, "A faiança portuguesa no Mosteiro de S. Joao de Tarouca (Portugal): da Uniao Ibérica à Refomra Pombalina", en Proceedings of the First International Conference of Portuguese Faience, Instituto de Arqueologia e Paleociências, Universidade Nova de Lisboa, Lisboa, 2016, p. 224.

73 VARELA GOMES, Mário, y CASIMIRO, Tânia Manuel, On the World's..., opus cit., p. 146.

74 BUSTO ZAPICO, Miguel, Cerámica de importación en el..., opus cit., pp. 1240-1258.

75 BUSTO ZAPICO, Miguel, Cerámica de importación en el..., opus cit., pp. 1242-1258. ellas son formas para utilizar en la mesa. Este motivo vegetal no muestra siempre la misma disposición, sino que podemos encontrarlo en el cuerpo de manera ondulada o perpendicular al fondo, siempre con trazos de gran sencillez. La ramita podría interpretarse como el árbol de la vida, un símbolo muy extendido por factores como la leyenda de San Gabriel ${ }^{76}$.

\section{Conclusiones}

Una característica que parece fundamental en todo este discurso, en torno a las imitaciones e influencias, es la capacidad del sector cerámico asturiano de proponer modelos culturales novedosos y de incorporar las corrientes estéticas del momento a sus elaboraciones. Esto se pone de manifiesto en el diseño del repertorio decorativo de Faro de Limanes y Miranda de Avilés, realizado para recoger todos los aspectos apetecibles del momento y para ser reproducido numerosas veces. Nuestro conocimiento sobre las producciones de los centros cerámicos asturianos de la Edad Moderna es aún muy inicial, Faro de Limanes es por ahora el más conocido, seguido de Miranda de Avilés, mientras que el resto de los centros que sabemos que existieron permanecen casi inéditos. Aun así, hemos podido apuntar influencias de un buen número de alfares europeos, por lo que es de suponer que según vayamos aumentando nuestro conocimiento sobre las producciones locales las influencias irán a más, señalándonos una realidad productiva muy rica y compleja.

Faro de Limanes se nutre de influencias de los principales centros ibéricos de cerámica como son Talavera de la Reina, Vila Nova o Coímbra. Se hacen además sentir algunas reminiscencias de alfares italianos y franceses. $\mathrm{Al}$ mismo tiempo, se reinterpretan motivos holandeses realizados en Delft, uno de los alfares europeos de mayor prestigio en la Edad Moderna, famoso por sus decoraciones influenciadas por la porcelana china. Este centro alfarero al interior de Asturias está enriqueciendo su producción con decoraciones surgidas en los grandes focos europeos. Miranda de Avilés no le va a la zaga, con influencias más que probables provenientes de Galicia y Portugal, a las que hay

\footnotetext{
76 FEITO, José Manuel, Cerámica tradicional..., opus cit., p. 49.
} 
que sumarles de manera clara las nacidas en Talavera de la Reina.

Estos pequeños centros productores asturianos, que podrían parecernos tan apartados de las vanguardias, van a tratar de satisfacer la de- manda de la población asturiana adaptándose de manera continua a sus gustos. Serán capaces de configurar una producción que asimila los cambios y que evoluciona a la par que lo hace la sociedad asturiana de la Edad Moderna.
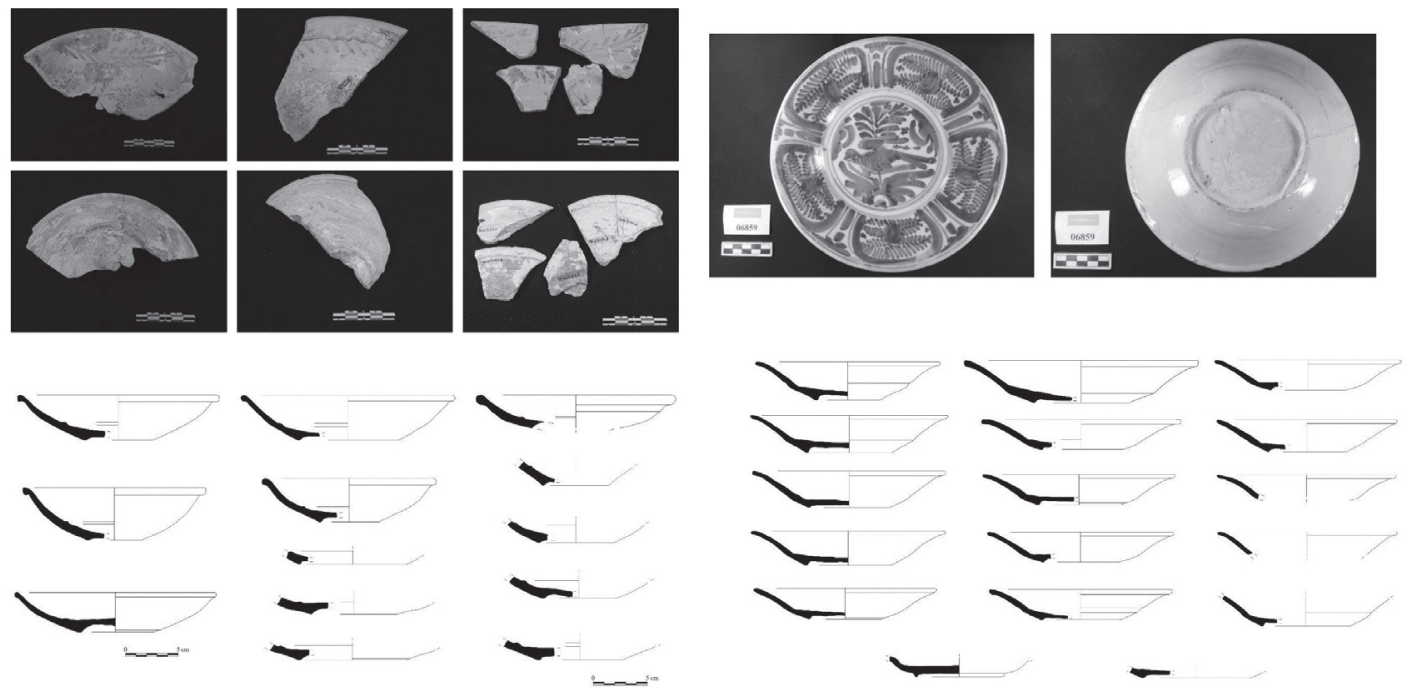

Fig. 5. Imitaciones mirandesas de piezas talaveranas. Columna izquierda: Miranda Esmaltada con azul - Plato I; columna derecha: plato, serie helechos, Talavera de la Reina (BUSTO ZAPICO, Miguel, Cerámica de importación en el..., opus cit., pp. 433-436), siglo XVII (PLEGUEZUELO HERNÁNDEZ, Alfonso, “Luces y sombras...", opus cit., p. 252). 